\title{
The Effect of Flocculant Type on Settling Properties of Fine Coal Tailings
}

\author{
DM Moyakhe, QP Campbell and E Fosso-Kankeu ${ }^{*}$
}

\begin{abstract}
Coal - water slurry handling is an integral part of any coal beneficiation process. This is due to the amount of fine coal tailing generated annually as the demand for resources increases. In conjunction with this occurrence and equally important is the water consumption associated with this process. To achieve efficient solid-liquid separation, the correct flocculant choice is crucial in this process. The interaction between the polymer and the slurry is vital in achieving optimum condition. Thus, in this study the influence of flocculant type and dosage on the settling of fine coal tailings was investigated.
\end{abstract}

Keywords - Coal, Fines, Flocculation, Sedimentation, Tailings.

\section{INTRODUCTION}

The development of mining has sourced major changes in the past few centuries. The most noticeable change being equipment automation and/or mechanization dominating the underground as well as surface mining industry. The development has brought about increased production volumes, and in contrast, a decrease in selectivity. Thus, an increase in refuse produced [1], with possible impact on the environment such as acid mine drainage formation [2-6].

The coal mining industry is similar; with increased volumes of coal produced and mineral matter refuse to report to the coal preparation plant. This resulted in the generation of a significant amount of wastewater with fine and colloidal particle tailings, composed of organic and inorganic matter which may often be reported in surface waters [7 - 16]. As a result, solid-liquid processes are thus necessary to manage wastewater slurry, and tailings disposed to recover the plant water [17].

Fine coal tailings handling is considered as the most challenging and exorbitant operation [18]. Thus, an appropriate dewatering method is essential. In practice, the prevalent method used is sedimentation with aid of flocculation in a thickener, using polymeric flocculants. The method has two significant parameters that evaluate flocculation performance [19]. The first parameter is the low water turbidity, since water

DM Moyakhe is with the School of Chemical and Minerals Engineering, North West University, Potchefstroom Campus, Private Bag X6001 2520, South Africa.

QP Campbell was with School of Chemical and Minerals Engineering, North West University, Potchefstroom Campus, Private Bag X6001 2520, South Africa.

E Fosso-Kankeu*, School of Chemical and Minerals Engineering, North West University, Potchefstroom Campus, Private Bag X6001 2520, South Africa. recovered at the thickener overflow is recycled to the plant. The suspended colloidal particles in the recycled water should be at the lowest level, eliminating any negative implications to the process. The second parameter, settling rate of the flocculated particles, has a direct effect on thickener capacity as well as flocculant performance. Thus, the challenge is achieving the lowest water turbidity level while maintaining high settling rate. Furthermore, optimizing polymeric flocculant properties and wastewater sludge $\mathrm{pH}$ is crucial in realizing preferred water clarity and settling rate.

The complex nature of flocculation process requires a precise determination of various properties of the wastewater sludge, this includes physical, chemical and electro-kinetic properties of the solid matter in the sludge. Moreover, the efficiency of the process is dependent on the use of accurate chemical reagents coagulants, flocculants, etc. - as well as the addition thereof [1].

The main objective of this study is to examine the physical, and mineralogical characteristics of fine coal tailings, investigate the flocculation performance of various types of flocculants and select the most appropriate. The type of flocculants based on their physical characteristics such as the molecular weight and the charge density was varied to study the flocculation mechanism of multi-component fine coal tailings slurry. A secondary objective is to determine the type of polymer current being used at the processing plant.

\section{EXPERIMENTAL}

\section{A. Material}

The coal slurry samples utilized in the experiments, were collected from a thickener feeding stream in a coal processing plant in Mpumalanga, South Africa. The representative samples were then transported to the laboratory in sample containers 200 liter drums - that operated as a stirring tanks as well. To obtain homogenous slurry samples, the samples underwent sufficient stirring.

The solid concentration, $\mathrm{pH}$, and density of the slurry were determined. Using the volumetric method, water hardness as well as the $\mathrm{Ca} 2+$ and $\mathrm{Mg} 2+$ concentrations were determined. By means of X-ray fluorescence (XRF) and X-ray diffraction (XRD), the chemical composition and mineral composition of the solid tailings were determined respectively.

High molecular weight polymer flocculants - provided by SENMIN, a division of AECI Mining Solutions Limited - were used in the settling tests. The generic - SENMIN approved properties of the flocculants are given in TABLE I. A 
homogenous solution of the flocculant - concentration $500 \mathrm{mg} / 1$ - was prepared with process water collected from the plant prior to each testing. The $\mathrm{pH}$ of the slurry was adjusted using hydrochloric acid to decrease the $\mathrm{pH}$, or lime solution to increase the $\mathrm{pH}$.

TABLE I: CHARACTERISTICS OF FLOCCULANTS

\begin{tabular}{llllll}
\hline \hline $\begin{array}{l}\text { Commercial } \\
\text { name }\end{array}$ & Name & Type & $\begin{array}{l}\text { Charge } \\
\text { density }\end{array}$ & $\begin{array}{l}\text { Molecular } \\
\text { weight }\end{array}$ & Supplier \\
\hline- & Floc A & - & - & & Plant \\
SENFLOC 5310 & Floc B & Non-ionic & - & High & SENMIN \\
SENFLOC 5330 & Floc C & Non-ionic & - & Medium & SENMIN \\
SENFLOC 5150 & Floc D & Anionic & Low & High & SENMIN \\
\hline \hline
\end{tabular}

\section{B. Method}

The flocculation experiments were carried out using batch settling jar tests. For each test, 1 liter of the original slurry - with a solid concentration of $4.71 \%$ - was transferred in a glass jar. The desired flocculant solution added to the testing jar. A lid was placed on the jar and mixing

The interface between the water and height of slurry the slurry as a function of time was recorded. From the recorded height versus time graph, the settling rate of the flocculated suspension is calculated. At time 15 minutes, the supernatant water was sampled to measure the turbidity of the clarified water.

\section{RESULTS AND DISCUSSION}

\section{A. Characterization of Fine Coal Tailings}

The XRD results, represented in TABLE II, indicate that the main minerals present in the coal tailings are Quartz, kaolinite, anatase, troilite, and magnetite in the order of decreasing quantity. The chemical composition depicted in Fig 1, as determined by XRF, shows the chemical composition. From the $\mathrm{XRF}$ results, the presence of $\mathrm{Al} 2 \mathrm{O} 3 \neg$ and $\mathrm{Fe} 2 \mathrm{O} 3$ validates the presence of clay minerals in the tailings [20]. The remaining fraction of the clay mineral $-56.58 \% \mathrm{SiO} 2$ - is attributed to quartz. The presence of Sulphur is validated by the Sulphur containing mineral troilite, with few carbonate minerals present in tailings, as confirmed by low $\mathrm{MgO}$ and $\mathrm{CaO}$ percentages. TABLE II, further shows a low slurry $\mathrm{pH}$.

\section{TABLE II: CHARACTERIZATION RESULTS OF THE COAL TAILINGS}

\begin{tabular}{ll}
\hline Slurry & \\
$\mathrm{pH}$ & 3.80 \\
Solid content $(\%)$ & 4.71 \\
$\mathrm{SG}$ & 1.03 \\
$\mathrm{Conductivity}(\mathrm{mS})$ & 3.10 \\
$\mathrm{Mg}^{2+}$ concentration $(\mathrm{mg} / \mathrm{L})$ & 200.43 \\
$\mathrm{Ca}^{2+}$ concentration $(\mathrm{mg} / \mathrm{L})$ & 561.01 \\
Solids & Quartz, kaolinite, anatase \\
Main components & troilite and magnetite \\
& \\
Process water & \\
$\mathrm{pH}^{\mathrm{C} H}$ & 4.20 \\
$\mathrm{Mg}^{2+}$ concentration $(\mathrm{mg} / \mathrm{L})$ & 2.01 \\
$\mathrm{Ca}^{2+}$ concentration $(\mathrm{mg} / \mathrm{L})$ & 170.05 \\
& 298.02 \\
\hline \hline
\end{tabular}

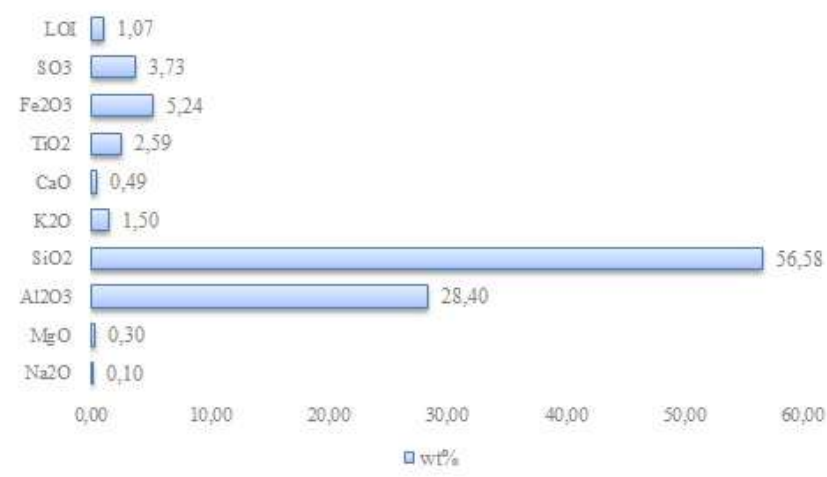

Fig 1: X-ray fluorescence results for the coal tailings

The characteristic of water in the slurry has a significant effect on the surface charge of the quartz mineral and coal that is present in the tailings. At low $\mathrm{pH}$, the surface charge on the clay and coal particles is said to be negative. Thus, low anionic to non-ionic flocculants are the most effective for low $\mathrm{pH}$ slurry[21, 22]

\section{B. Flocculation Experiments}

The settling tests were performed with the aid of different types of flocculants varying the desired dosages as presented in TABLE I. Fig 2, reports the effect of polymer type and dosage on the settling rate of the coal tailings. Floc A, presented in TABLE II, is the polymer currently employed at the coal preparation plant, and no information was given for this polymer. Also in Fig 2, Floc D - low anionic polymer, the results show an increase in settling rate with an increase in dosage until a maximum was reached. In this case a maximum of 305 $\mathrm{mm} / \mathrm{min}$ at $97 \mathrm{~g} / \mathrm{ton}$. Floc $\mathrm{B}-\mathrm{C}$, the non-ionic polymers, however reached higher settling rates at higher polymer dosages compared to the low charged polymer. It is assumed that conformation of the polymer chain is the main contributor to the difference observed between the low anionic and non-ionic polymers [23]. Due to the low pH of the slurry, the low anionic flocculant is unable to extend the chains effectively due to the charge in the functional groups of the polymer. Thus, the bridging mechanism used by this polymer to form bigger flocs is retarded. Non-ionic flocculants relies on the hydrogen bonding for effective floc formation, since the surface charge on the clay minerals, kaolinite and quartz, is negative[1]. The hydrogen bonding aids the formation for floc and hence achieves high settling rates. Furthermore, a difference is detected between Floc B and Floc C in Fig 2. The settling rate of Floc B and C, at dosage $193 \mathrm{~g} / \mathrm{ton}$, is $1110 \mathrm{~mm} / \mathrm{min}$ and $745 \mathrm{~mm} / \mathrm{min}$ respectively. This difference is due to the difference of molecular mass, the settling rate increases with an increase in mass for the same dosage. 


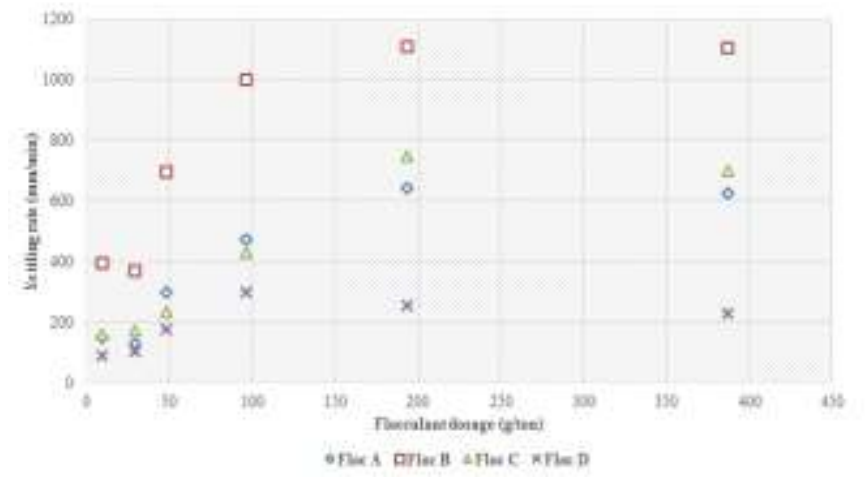

Fig 2: Settling rate verses flocculant dosage

The performance of Floc A, is similar to that of Floc C. This means that Floc A behaves as a non-ionic polymer. Fig 3, shows how the turbidity of the suspension varied with the change of polymer dosage. At low polymer dosage, colloidal particles destabilization is not sufficient [24]. Thus not many colloidal particles forms floc sizes required for settling. As a result, high turbidity values were recorded at low flocculant dosages. As the dosage increase, the lowest turbidity value is reached for all four polymers. Flocs A, C, and D reach lowest turbidity values at dosage $97 \mathrm{~g} /$ ton, while for Floc B, the lowest turbidity value is achieved at dosage $48 \mathrm{~g} /$ ton. Furthermore, at high dosages the high selling rates results in the dispersion of smaller floc. Thus, surface charges of the colloidal particles particularly the kaolinite in the system, experiences repulsion forces stabilizing the colloidal suspension [22].

\section{CONCLUSION}

The characterization of tailings from the coal processing plant showed that the clays kaolinite and quartz to the main constituents of the tailings. In conjunction with low slurry $\mathrm{pH}$, it was showed that choosing the correct polymer for solid-liquid separation is a complex procedure.

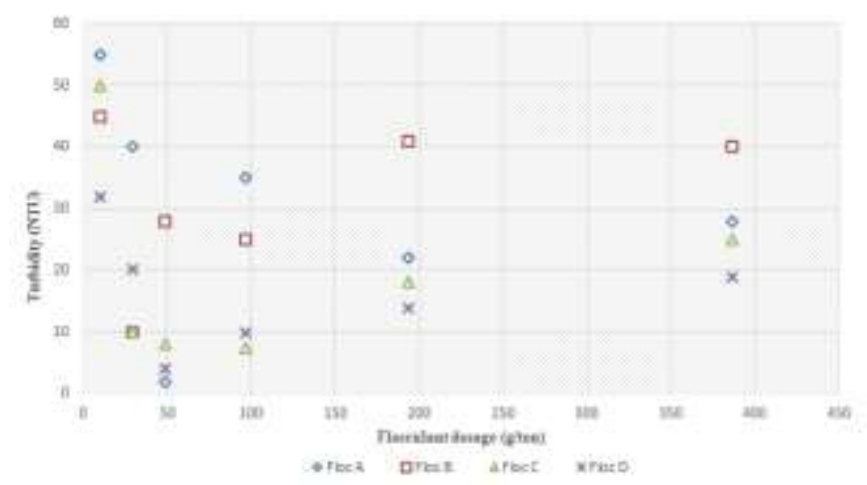

Fig 3: Turbidity verses flocculant dosage

Various factors need to be considered to in order to make informed choice. Different properties of polymers yielded different results. Although, it was shown that for the slurry with a low $\mathrm{pH}$, a non-ionic flocculant is most effective due to the electrostatic forces that results from the negative charge on the surface of the particles.

It was also clear that the molecular mass of the flocculants plays an important role. Despite the lack of information regarding the properties of Floc $\mathrm{A}$, which is the polymer from the processing plant, performance similar to a non-ionic polymer was observed. The optimum dosage for Floc A, B, and $\mathrm{C}$ was shown to be $193 \mathrm{~g} /$ tom and $97 \mathrm{~g} /$ ton for Floc D. For the system, if settling is the most important factor, then dosage of Floc B at $193 \mathrm{~g} /$ ton will be recommended. However, if water turbidity is the most important parameter, it will be advise to dose with Floc A at $48 \mathrm{~g} /$ ton.

\section{ACKNOWLEDGMENT}

The authors are grateful to the sponsor from the North-West University and the National Research Foundation in South Africa. Any opinion, findings and conclusions or recommendations expressed in this material are those of the authors and therefore the NRF does not accept any liability in regard thereto. The contribution of SENMIN is greatly acknowledged.

\section{REFERENCES}

[1] E .Sabah, I.C., An evalution procedure for flocculation of coal preparation plant tailings. Water Research, 2004. 28: p. 1542-1549.

[2] Fosso-Kankeu E, Mulaba-Bafubiandi A, Mamba BB, Barnard TG. 2011. Assessing the effectiveness of a biological recovery of nickel from tailings dumps. Journal of Minerals Engineering.Vol 24, pp 470-472.

[3] Elvis Fosso-Kankeu, Alusani Manyatshe, Frans Waanders. 2017. Mobility potential of metals in acid mine drainage occurring in the Highveld area of Mpumalanga Province in South Africa: Implication of sediments and efflorescent crusts. International Biodeterioration and Biodegradation. 119: 661-670.

[4] Elvis Fosso-Kankeu, Frans Waanders, Antoine F. Mulaba-Bafubiandi and Sibusiso Sidu. 2015. Leachability of suspended particles in mine water and risk of water contamination. $10^{\text {th }}$ ICARD/IMWA 2015; $10^{\text {th }}$ International Conference on Acid Rock Drainage \& IMWA Annual Conference. 21-24 April 2015 Santiago-Chile. Editors: Adrian Brown, Charles Bucknam, Joanna Burgess, Manuel Carballo, Devin Castendyk, Linda Figueroa, Lisa Kirk, Virginia McLemore, James McPhee, Mike O'Kane, Robert Seal, Jacques Wiertz, David Williams, Ward Wilson, Christian Wolkersdorfer. ISBN: 978-956-9393-28-0. Chap 4. Pp 1-9.

[5] Elvis Fosso-Kankeu, Frans Waanders, and Wiehan Botes. 2015. Recovery of Base Metals from Mine Tailings Dumps collected in the Vicinity of Potchefstroom: Leaching assisted by Complexing Agent. $7^{\text {th }}$ International Conference on Latest Trends in Engineering and Technology (ICLTET' 2015), November 26-27, 2015 Irene, Pretoria (South Africa). Editors: E. Muzenda and T Yingthawornsuk. ISBN: 978-93-84422-58-5.

[6] Fosso-Kankeu, E., Manyatshe, A., Munyai, A., Waanders, F., 2016. AMD formation and dispersion of inorganic pollutants along the main stream in a mining area. In: Drebenstedt, C. \& Paul, M.: IMWA 2016 Mining Meets Water - Conflicts and Solutions. - p. 391 - 397; Freiberg/Germany (TU Bergakademie Freiberg).

[7] Fosso-Kankeu E, Mulaba-Bafubiandi A, Mamba BB, Barnard TG. 2009. Mitigation of $\mathrm{Ca}, \mathrm{Fe}$, and $\mathrm{Mg}$ loads in surface waters around mining areas using indigenous microorganism strains. Journal of Physics and Chemistry of the Earth, Vol 34, pp 825-829.

[8] Fosso-Kankeu E, Mulaba-Bafubiandi A, Mamba BB, Marjanovic L, Barnard TG. 2010. A comprehensive study of physical and physiological parameters that affect biosorption of metal pollutants from aqueous solutions. Journal of Physics and Chemistry of the Earth, Vol 35, pp 672-678.

[9] A.H. Munyai, E. Fosso-Kankeu, F. Waanders. 2016. Biological influence on the mobility of metals from mine tailing dump located in Krugersdorp area. International Journal of Science and Research. ISSN: 2319-7064. 5(4): 1396-1403.

[10] Alusani Manyatshe, Elvis Fosso-Kankeu, Divan van der Berg, Nico Lemmer, Frans Waanders, Hlanganani Tutu. 2017. Metal retention 
potential of sediment and water quality in the Mooi River, South Africa. Desalination and Water Treatment. doi: 10.5004/dwt2017.20222.

[11] A. Manyatshe, E. Fosso-Kankeu, D. van der Berg, N. Lemmer, F. Waanders, H. Tutu. 2017. Dispersion of inorganic contaminants in surface water in the vicinity of Potchefstroom. Physics and Chemistry of the Earth. 100: 86-93.

[12] E. Fosso-Kankeu, R. Kaitano, F. Waanders, A.F. Mulaba-Bafubiandi. 2014. Soil Quality in the Basin of Mine Effluents and the Potential of Alleviation of Metal Dispersion. An Interdisciplinary Response to Mine Water Challenges. International Mine Water Conference, August 2014 Xuzhou China. Editors, Sui, Sun \& Wang (Eds). 2014 China University of Mining andTechnology Press, Xuzhou, ISBN: 978-7-5646-2437-8. Pp374-378.

[13] Elvis Fosso-Kankeu, Alusani Manyatshe, Divan van der Berg, Nico Lemmer, Frans Waanders, and Tutu Hlanganani. 2015. Contaminants in Sediments across the Mooi and Vaal Rivers Network in The Vicinity of Potchefstroom. $7^{\text {th }}$ International Conference on Latest Trends in Engineering and Technology (ICLTET' 2015), November 26-27, 2015 Irene, Pretoria (South Africa). Editors: E. Muzenda and T Yingthawornsuk. ISBN: 978-93-84422-58-5.

[14] Elvis Fosso-Kankeu, Frans B. Waanders, and Ashley H. Munyai. 2015. Susceptibility of Metals Release from Tailings Dumps Located In the Krugersdorp Area. $7^{\text {th }}$ International Conference on Latest Trends in Engineering and Technology (ICLTET' 2015), November 26-27, 2015 Irene, Pretoria (South Africa). Editors: E. Muzenda and T Yingthawornsuk. ISBN: 978-93-84422-58-5.

[15] Elvis Fosso-Kankeu, Divan P. Van der Berg, Frans Waanders, Alusani Manyatshe, Nico Lemmer, and H. Tutu. 2015. Mapping of surface water quality in the vicinity of Potchefstroom based on mining pollutants. $7^{\text {th }}$ International Conference on Latest Trends in Engineering and Technology (ICLTET' 2015), November 26-27, 2015 Irene, Pretoria (South Africa). Editors: E. Muzenda and T Yingthawornsuk. ISBN: 978-93-84422-58-5.

[16] Manyatshe A, Fosso-Kankeu E, Van Der Berg D, Lemmer N, Waanders F, Tutu H. 2016. Assessment of seasonal variation in surface water quality of the Mooi and Vaal Rivers network, South Africa. International Conference on Advances in Science, Engineering, Technology and Natural Resources (ICASETNR-16) Nov. 24-25, 2016, Parys - South Africa. ISBN: 978-93-84468-79-8.

[17] E. Sabah, Z.E.E., Interaction mechanism of flocculants with coal waste slurry. Fuel, 2006. 85: p. 350-359.

[18] Shravan Kumara, N.R.M.S.B., Flocculation Studies of Coal Tailings and Development of 'Settling Index'. International Journal of Coal Preparation and Utilization, 2015.

[19] Oruç, F., S. Özgen, and E. Sabah, An enhanced-gravity method to recover ultra-fine coal from tailings: Falcon concentrator. Fuel, 2010. 89(9): p. 2433-2437.

[20] Sabah, F.O.a.E., Effect of mixing conditions on flocculation performance of fine coal tailings, in International Mineral Processing Congress. 2006: Istanbul-Turkey. p. 1192-1197.

[21] Sabah, E., H. Yüzer, and M.S. Çelik, Characterization and dewatering of fine coal tailings by dual-flocculant systems. International Journal of Mineral Processing, 2004. 74(1-4): p. 303-315.

[22] I. Cengiz, E.S., S. Ozgen, H. Akyildiz, Flocculation of Fine Particles in Ceramic Wastewater Using New Types of Polymeric Flocculants. Journal of Applied Polymer Science, 2009. 112: p. 1258-1264.

[23] Z. E. ERKAN, E.S., T. KAVAS, İ. CENGIZ, Evaluation of - $0.045 \mathrm{~mm}$ Tailings in the Tunçbilek Coal Preparation Plant Wastewater as a Cement Raw Material. 2004, ResearchGate.

[24] E. SABAH, C.A., FLOCCULATION PERFORMANCE OF FINE PARTICLES IN TRAVERTINE SLIME SUSPENSION. Physicochemical Problems of Mineral Processing, 2012. 42(2): p. 555-556.

The corresponding author is currently an Associate Professor in the School of Chemical and Minerals Engineering at the North-West University (Potchefstroom). He is an NRF rated researcher who has published journal articles, book chapters and book.

Prof Elvis Fosso-Kankeu has been the recipient of several merit awards. 